\title{
Correction to: Newspaper reporting of the April 2007 eruption of Piton de la Fournaise part 1: useful information or tabloid sensationalism?
}

Andrew J. L. Harris ${ }^{1 *}$ and Nicolas Villeneuve ${ }^{2,3}$

\section{Correction}

In the publication of this article (Harris \& Villeneuve 2018), there is an error in Fig. 1.

The error:

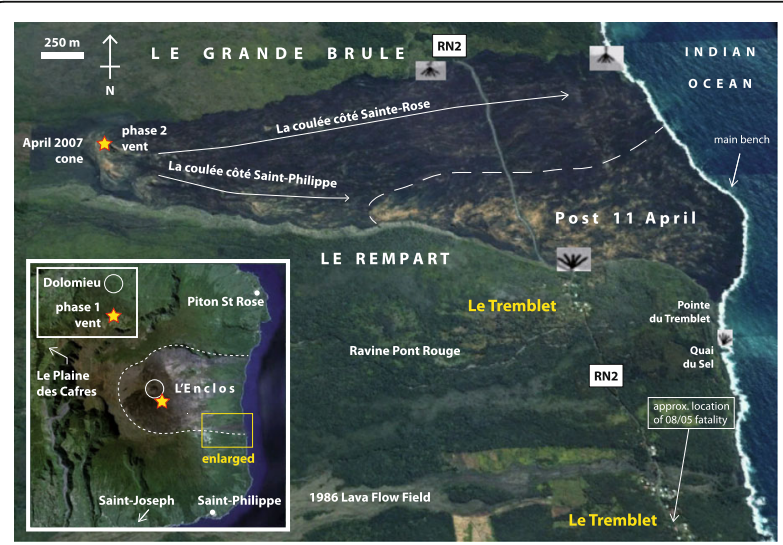

Fig. 1 Google Earth image of the 2007 flow field with all locations referred to in the text. Image is from 31/12/2008 (Image: NASA) and includes locations of the four controlled viewing points opened up on 4 April 2007, as announced in JIR on 5 (p. 9) and 6 April (P. 7). Inset is a Piton de la Fournaise location map on a Google Earth (๔ 2015 Google) image (Image ๔ 2015 Digital Globe); data: SIO, NOAA, U.S. Navy, NGA, GEBCO. Labelling of 'L'Enclos' is based on the geographical location terms used by the newspapers and locals and refers to the entire caldera. It thus includes L'Enclos Fouqué (upper part of the caldera), Les Grandes Pentes (middle part) and Le Grand Brûlé (coastal part)
Should instead read:

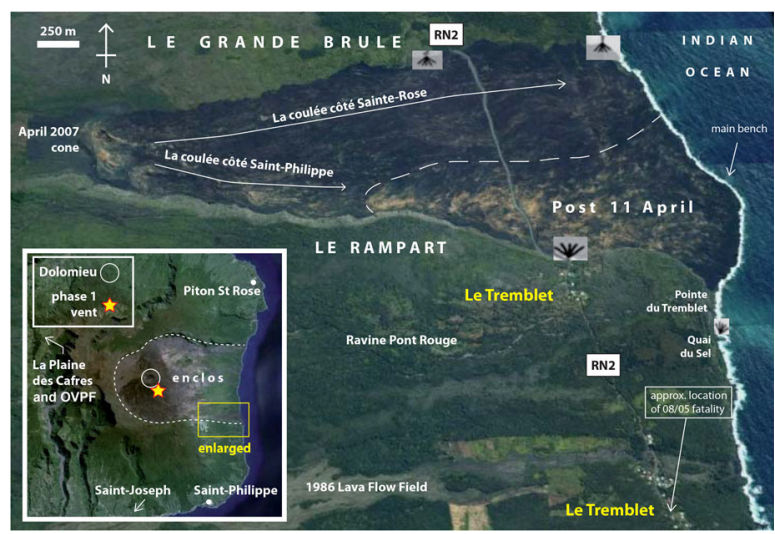

Fig. 1 Google Earth image of the 2007 flow field with all locations referred to in the text. Image is from 31/12/2008 (Image: NASA) and includes locations of the four controlled viewing points opened up on 4 April 2007, as announced in JIR on 5 (p. 9) and 6 April (P. 7). Inset is a Piton de la Fournaise location map on a Google Earth (๔ 2015 Google) image (Image ๔ 2015 Digital Globe); data: SIO, NOAA, U.S. Navy, NGA, GEBCO. Labelling of 'L'Enclos' is based on the geographical location terms used by the newspapers and locals and refers to the entire caldera. It thus includes L'Enclos Fouqué (upper part of the caldera), Les Grandes Pentes (middle part) and Le Grand Brûlé (coastal part)

The original article has been corrected (Harris \& Villeneuve 2018).

\footnotetext{
Author details

${ }^{1}$ Université Clermont Auvergne, CNRS, IRD, OPGC, Laboratoire Magmas et Volcans, 6 Avenue Blaise Pascal, 63178 Aubière, France. ${ }^{2}$ Observatoire Volcanologique du Piton de la Fournaise, Institut de Physique du Globe de Paris, Sorbonne Paris Cité, CNRS, Université Paris Diderot, F-75005 Paris, France. ${ }^{3}$ Laboratoire GéoSciences Réunion, Université de La Réunion, Institut de Physique du Globe de Paris, Sorbonne Paris Cité, CNRS, F-97744 Saint Denis, Paris, France.
}

\footnotetext{
* Correspondence: andrew.harris@uca.fr

'Université Clermont Auvergne, CNRS, IRD, OPGC, Laboratoire Magmas et Volcans, 6 Avenue Blaise Pascal, 63178 Aubière, France
}

(c) The Author(s). 2018 Open Access This article is distributed under the terms of the Creative Commons Attribution 4.0 International License (http://creativecommons.org/licenses/by/4.0/), which permits unrestricted use, distribution, and reproduction in any medium, provided you give appropriate credit to the original author(s) and the source, provide a link to the Creative Commons license, and indicate if changes were made. 
Received: 1 June 2018 Accepted: 1 June 2018

Published online: 30 June 2018

Reference

Harris AJL, Villeneuve. Newspaper reporting of the April 2007 eruption of Piton de la Fournaise part 1: useful information or tabloid sensationalism? J Appl. Volcanol. 2018;7:4. https://doi.org/10.1186/s13617-018-0073-1. 